\title{
Incidental cardiac papillary fibroelastoma: a management dilemma
}

\author{
Lovely Chhabra, Saurabh Joshi, Vinod Kumar Chaubey, Sudesh Kaul
}

Department of Internal Medicine, Saint Vincent Hospital, University of Massachusetts Medical School, Worcester, Massachusetts, USA

\section{Correspondence to Dr Lovely Chhabra, lovids@hotmail.com}

\footnotetext{
To cite: Chhabra L, Joshi S, Chaubey VK, et al. BMJ Case Rep Published online: [please include Day Month Year] doi:10.1136/bcr-2013200133
}

\section{DESCRIPTION}

A 78-year-old woman with a history of diastolic heart failure and paroxysmal atrial fibrillation (PAF) presented after a syncope. She was on warfarin therapy for PAF. Her cardiovascular examination was essentially unremarkable. Her orthostatic vital signs were stable and electrocardiogram revealed a normal sinus rhythm. Laboratory examination was unremarkable and her international normalised ratio (INR) was 2.5. Telemetry monitoring was largely unremarkable. Transthoracic echocardiography showed a mobile pedunculated mass $(2.2 \mathrm{~cm}$ in the largest dimension) on the ventricular aspect of the anterior mitral valve, with a homogeneous speckled pattern and a characteristic stippling along the edges, most likely consistent with an incidental cardiac papillary fibroelastoma (CPFE) (figure 1 and video 1). Transoesophageal echocardiography was also consistent with similar findings of CPFE (video 2). The patient was discharged with a holter monitor with a discharge plan for follow-up with cardiothoracic surgery.

Primary cardiac tumours are rare with an incidence of less than $0.03 \% .{ }^{1}$ CPFE is the second most common cardiac tumour after myxoma. ${ }^{2}$ More than 70\% of CPFE are benign, and only $8 \%$ are papillary fibroelastomas, mostly located on the heart valves. CPFE is more commonly seen on the aortic valve closely followed by the mitral valve. It is usually more prevalent in middle-aged women. More than half of the patients are asymptomatic. ${ }^{3}$ The common complications include transient ischaemic attack, stroke, syncope, acute myocardial infarction and cardiac arrest, due to either embolism or mechanical obstruction. ${ }^{3}$ It is usually

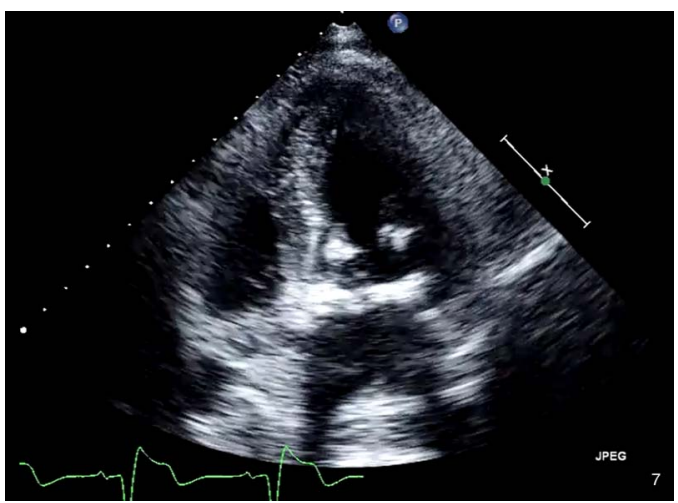

Video 1 Transthoracic echocardiogram shows a mobile pedunculated mass $(2.2 \mathrm{~cm}$ in the largest dimension) on the ventricular aspect of the anterior mitral valve, with a homogeneous speckled pattern and a characteristic stippling along the edges, most likely consistent with an incidental cardiac papillary fibroelastoma.

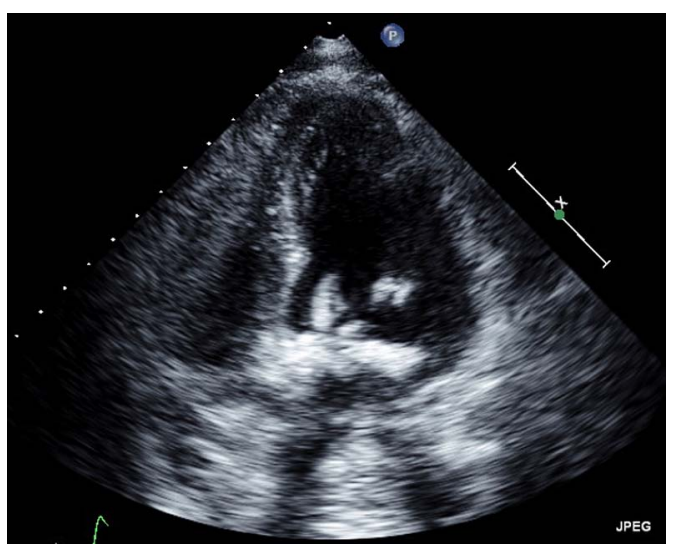

Figure 1 Transthoracic echocardiogram shows a mobile pedunculated mass $(2.2 \mathrm{~cm}$ in the largest dimension) on the ventricular aspect of the anterior mitral valve, with a homogeneous speckled pattern and a characteristic stippling along the edges, most likely consistent with an incidental cardiac papillary fibroelastoma.

diagnosed on echocardiography and can be confirmed with biopsy. In typical cases, papillary fibroelastoma phenotypically resembles a sea anemone.

Although CPFE is rare, its associated complications can be serious and life-threatening. When symptomatic, the recommended treatment is surgical excision. The dilemma occurs when it is diagnosed incidentally. There are no clear guidelines on the management of asymptomatic CPFE. Because of their potential for causing cerebral and coronary embolisation, many experts recommend surgical excision even in asymptomatic patients. Thus, it

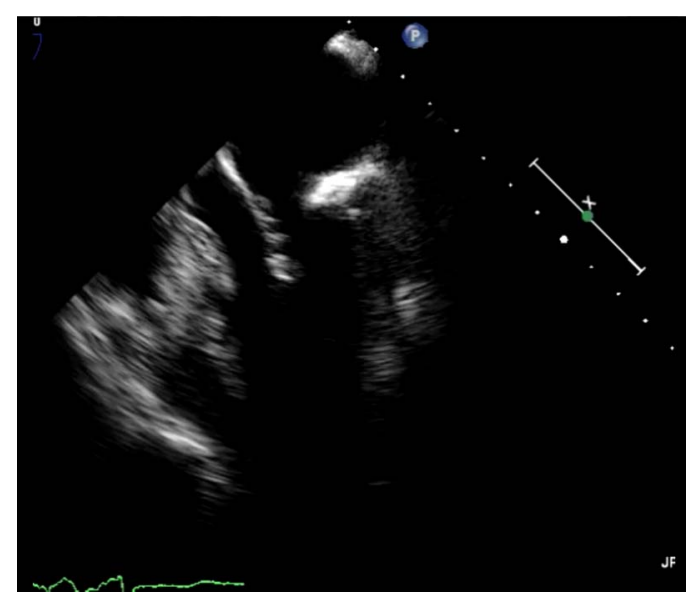

Video 2 Transesophageal echocardiogram is again consistent with findings of cardiac papillary fibroelastoma. 
would be advisable that if a patient is a low-risk surgical candidate, excision should be undertaken, especially if the tumour is left sided, mobile and more than $1 \mathrm{~cm}$ in size. ${ }^{4}$

\section{Learning points}

- Cardiac papillary fibroelastoma (CPFE) is the second common primary cardiac tumour with the most common location being aortic valve, followed by mitral valve.

- Because of the potential risk of embolism and mechanical obstruction, it can lead to serious morbidity or life-threatening situation.

- Symptomatic CPFE should be managed surgically, and surgical excision should also be strongly considered for asymptomatic patients especially if the tumour is left-sided, mobile and greater than $1 \mathrm{~cm}$ in size.
Contributors All authors have contributed significantly in writing and revising the manuscript. All authors have reviewed the manuscript before submission.

Competing interests None.

Patient consent Obtained.

Provenance and peer review Not commissioned; externally peer reviewed.

\section{REFERENCES}

1 McAllister HA Jr. Primary tumors and cysts of the heart and pericardium. Curr Prob/ Cardiol 1979:4:1-51

2 Mariscalco G, Bruno VD, Borsani $P$, et al. Papillary fibroelastoma: insight to a primary cardiac valve tumor. J Card Surg 2010;25:198-205.

3 Val-Bernal JF, Mayorga M, Garijo MF, et al. Cardiac papillary fibroelastoma: retrospective clinicopathologic study of 17 tumors with resection at a single institution and literature review. Pathol Res Pract 2013;209:208-14.

4 Boodhwani M, Veinot JP, Hendry PJ. Surgical approach to cardiac papillary fibroelastomas. Can J Cardiol 2007:23:301-2.

Copyright 2013 BMJ Publishing Group. All rights reserved. For permission to reuse any of this content visit http://group.bmj.com/group/rights-licensing/permissions.

BMJ Case Report Fellows may re-use this article for personal use and teaching without any further permission.

Become a Fellow of BMJ Case Reports today and you can:

- Submit as many cases as you like

- Enjoy fast sympathetic peer review and rapid publication of accepted articles

- Access all the published articles

- Re-use any of the published material for personal use and teaching without further permission

For information on Institutional Fellowships contact consortiasales@bmjgroup.com

Visit casereports.bmj.com for more articles like this and to become a Fellow 